\title{
Stop traffick: Tackling demand for sexual services of trafficked women and girls
}

\author{
Edward Keegan ${ }^{1}$ and Nusha Yonkova ${ }^{2}$
}

\begin{abstract}
The research focuses on the characteristic, knowledge, and experiences of buyers of sex, focusing on human trafficking and exploitation. Recognising that those trafficked for sexual exploitation are often exploited in the commercial sex industry, the research adopts an understanding of 'demand' in the context of human trafficking which includes demand for women in prostitution. In order to study buyers, a mixture of quantitative and qualitative research tools was used, including online questionnaires and face-to-face interviews. Through these methods, a total of 763 buyers engaged with the research, across four EU Member States (Ireland, Finland, Bulgaria and Lithuania). A number of important findings emerged in the research. Buyers interviewed were seen to have a complex view of sellers. They overwhelmingly viewed the sale of sex as a transaction between two consenting adults, but also saw sellers as different from other women. At the same time, although up to a third of buyers had witnessed or suspected exploitation, a gap emerged with regard to those who had reported such fears. Finally, irrespective of their knowledge of human trafficking, or measures targeting those who knowingly purchase sex from trafficked victims, buyers rarely considered trafficking when purchasing sex.
\end{abstract}

Keywords: human trafficking; sexual exploitation; prostitution; demand; buyers

1. Anti-Trafficking Coordinator, Immigrant Council of Ireland

2. Gender and Anti-Trafficking Expert, Immigrant Council of Ireland

Address for correspondence: edward@immigrantcouncil.ie

Date of first (online) publication:2nd October 2018 


\section{Introduction}

In recent years, there is increased recognition that sex buyers are an important component in the trafficking chain. Recognising the role of buyers in the demand for victims of human trafficking for sexual exploitation, the research explores the intersection between the purchase of sex and trafficking. Using a combination of quantitative and qualitative methods, consisting of online surveys and face to face interviews, the research explores the characteristics and experiences of buyers in Ireland, Finland, Bulgaria and Lithuania, particularly with regards their understanding and experiences of exploitation when purchasing sex. The research forms part of the European Commission funded transnational STOP Traffick: Tackling Demand for Sexual Services of Trafficked Women and Girls, led by the Immigrant Council of Ireland (Yonkova and Keegan, 2014).

Given the importance of anonymity to those involved in the purchase of sex, buyers represent a hard to reach population. Consequently, they pose a number of difficulties for researchers. The different methods used for overcoming such difficulties included the use of online research tools which could ensure the anonymity of sellers. Overall, 337 buyers from Ireland $(n=58)$, Finland $(n=208)$, Lithuania ( $n=34)$ and Bulgaria ( $n=37)$ participated in the research. The research project on which this paper is based included an online survey in Cyprus. However, the results from Cyprus have been excluded owing to a lack of available information on the methodology employed to recruit buyers (who represent the hard-to-reach population studied here) for this component of the research.

Notable findings from the research include that a significant proportion of buyers have encountered sellers they believe were exploited; that there is a gap between the number of buyers who encountered such sellers and those who considered or actually contacted authorities; and that buyers rarely consider human trafficking when purchasing sex, likely owing to a complex view of sellers and a pre-existing understanding of prostitution as an act between two consenting adults.

\section{Understanding demand in the context of human trafficking for sexual exploitation}

The importance of 'demand' in the context of human trafficking can be attributed to its recognised role as a driving force for trafficking. For example, Article 6 of the Council of Europe Convention on Action against Trafficking in Human Beings requires States Parties to the Convention to take a number of measures to 'discourage the demand that fosters all forms of exploitation of persons, especially women and children, that leads to trafficking.... Similarly, Article 18 of the European Union's Anti-Trafficking Directive requires that Member States adopt measures to 'discourage and reduce the demand that fosters all forms of exploitation related to trafficking 
in human beings'.

The focus on sex buyers in research on human trafficking can be attributed to the understanding of 'demand' which has emerged in anti-trafficking literature. Within this, 'demand' - in the context of trafficking in human beings for sexual exploitation - has come to be seen as a multifaceted phenomenon, driven by both actors and contexts. These include end-users or buyers, third-party organisers, state policies and societal norms.

In the context of trafficking for sexual exploitation, the first actor identified as creating demand is the buyer. According to Hughes (2004), buyers are responsible for what has been termed primary demand. Anderson and O'Connell Davidson (2002) adopt a similar, yet distinct, understanding of the role of the buyer in creating demand. Hughes (2004) attributes the role of buyers in creating demand to their decision-making process, which she suggests does not consider the status of the seller. As a result, it is all buyers who generate demand for trafficked sellers. This approach is challenged by Anderson and O'Connell Davidson, who have formulated an understanding of customer demand that focuses on particular markets within the sex industry. This distinction will be explored in greater detail below.

The second group of actors identified as generating demand for trafficking victims are those profiting from the sex industry. These include 'traffickers, pimps, brothel owners, and supporting corrupt officials' (Hughes, 2004: 2). The involvement of such actors in the 'demand' for victims has been agreed upon by the growing body of economic literature on human trafficking (Wheaton et al, 2010; Danailova-Trainor and Belser, 2005). While Anderson and O'Connell Davidson (2002, pp. 37-39) have agreed with the involvement of third-party organisers of prostitution in driving demand for trafficking victims, they believe that only a minority of such actors are involved. In addition, Hughes has included a number of governments in her understanding of demand. These include those governments who have legalised or regulated the selling of sex (Hughes, 2005, p. 8). Anderson and O'Connell Davidson have adopted a different understanding of the role played by government policies in creating demand. They have accused policies that effectively tie migrant sellers to their employers or fail to extend labour laws to their particular situation as creating a carte blanche for employers to treat them as they wish (Anderson and O'Connell Davidson, 2002, pp. 40-41).

The final factor identified as influencing demand is the culture that has normalised the purchasing of sex (Hughes, 2004, pp. 2-3).

The European research project from which this article has been developed only focuses on primary demand. Consequently, this article similarly focuses on those driving demand at this level, buyers.

In the context of trafficking for the purpose of sexual exploitation, there has been divergence of opinions on the role of end users or buyers in creating 'demand' for victims of trafficking. The question that has been raised is whether all buyers of sexual services create this demand that fosters human trafficking or is it only specific 
subsets of buyers. Furthermore, it is questioned whether it is buyers or organisers who create demand for trafficking victims. Each of these approaches is considered below under the headings of 'specific demand' and 'general demand'.

\section{Specific demand}

Specific demand refers to approaches that focus on particular markets or demands within the sex industry, as well as the role of third-party organisers in creating a particular demand for trafficked sellers. Markets identified as creating demand for trafficking victims include those for specific racial or ethnic groups, for women with specific language capabilities, catering to migrant workers, and for virgins or adolescent girls, amongst others (Hughes, 2004, pp. 21-27). In respect of the market for the racial or ethnic 'other', there is not a straightforward link between the demands of buyers and the supply of trafficking victims. It will likely only arise where there is a significant amount of persons from a specific racial or ethnic background already present within the market, which in turn creates a demand, which may lead to persons being trafficked (Anderson and O'Connell Davidson, 2002, pp. 33-34).

Additional factors identified as having the potential to create demand for trafficked persons are where there is a demand for cheap sex and where third parties are involved. Where prices are low, it is likely that there will be criminal elements and exploited persons (Anderson and O'Connell Davidson, 2002, p. 31). The potential involvement of third-party organisers in the demand for trafficked persons will likely stem from economic considerations - their profit will increase with the use of trafficked persons (Anderson and O'Connell Davidson, 2002, pp. 37-40). According to Anderson and O'Connell Davidson, those involved in this area of the sex industry are not a homogenous group in regards their practices. As a result, it will not be the involvement of any third party, but only some that may drive demand for trafficking victims (Anderson and O'Connell Davidson, 2002, pp. 38-39).

Danailova-Trainor and Belser have presented a similar, third-party driven understanding of 'demand'. Within this, the market for trafficking victims is based on transactions between traffickers and third-party organisers (Danailova-Trainor and Belser, 2006, pp. 2-3). According to Danailova-Trainor and Belser (2006, p. 3 ), any specific demand for trafficking victims emerges from these third-party organisers. Wheaton et al (2010) produced a similar model of the economics of human trafficking. In this, the trade that occurs in the human trafficking 'market' is based on a 'business-to-business' model. Consequently, 'in the human trafficking market, traffickers act as intermediaries to provide employers, who use trafficked labour, with workers' (Wheaton et al, 2010, p. 123).

The role of buyers or end users in creating demand for trafficked persons is uncertain in these economic models. While they may not explicitly request trafficked 
sellers, considerations over price may be responsible for the decisions of third-party organisers to use trafficked sellers (Danailova-Trainor and Belser, 2006, p. 3). It is here where the overlaps between a general demand for sellers and the demand for trafficking victims can be seen. At the same time, however, the presence of trafficking victims in areas of the commercial sex industry where prices are higher, such as expensive escort services, suggests that it is more difficult to distinguish areas of the industry where trafficking victims are exploited (Kelleher et al, 2009).

\section{General demand}

General demand refers to an approach that does not attempt to distinguish or separate the demands for trafficked and non-trafficked sellers. This approach recognises that buyers are most often uninterested in the status of sellers. According to Hughes (2004, p. 3), it is not something they consider or take into account when purchasing sex. Similarly, the economic models used to understand human trafficking, discussed above, do not consider a specific 'demand' for trafficking victims (Wheaton et al, 2010; Danailova-Trainor and Belser, 2006, p. 3). According to these models, the status of a seller is not a concern for the buyer. This approach, which can be termed the inseparability of demand, has gained traction owing to research which suggests a correlation between increased demand and levels of human trafficking (Cho et al, 2013). According to the findings of Cho et al (2013), based on quantitative and qualitative evidence, a state's regulation of prostitution has an impact on levels of human trafficking. Thus, 'on average, countries with legalized prostitution experience a large degree of reported human trafficking inflows' (Cho et al, 2013, pp. 75-76).

Considering the above, particularly the role played by buyers within each understanding of 'demand', this research adopts a customer driven approach to the term 'demand', placing the demand for victims of trafficking for sexual exploitation within the wider demand for sellers. Consequently, empirical research was carried out on buyers of sex in general. Owing to the generally hidden nature of the practice of purchasing sex and the importance of anonymity to buyers, conducting such research, however, poses a number of problems for researchers.

\section{Methodology}

In order to study this hard to reach population and better understand sex buyers, particularly in the context of the intersection between the purchase of sex and trafficking in human beings for sexual exploitation, the research relied on mixed methods for data collection; combining quantitative and qualitative components. 


\section{Online surveys}

The quantitative component of the research consisted of online surveys conducted in Ireland and Finland. The researchers adopted a non-probability approach to sampling. Adoption of such an approach was based on the purpose of the online surveys. These were intended as a means of collecting data on the characteristics and subjective experiences of buyers in Ireland and Finland. The online surveys were not used to measure the percentage of persons who had purchased sex in Ireland and Finland and thus it was not required to use probability based sampling. Furthermore, while there have been a small number of studies conducted in Ireland and Finland on the purchase of sex, there is not enough pre-existing information that would have allowed for us to target a representative sample of buyers. At the same time, it was not possible to weight responses, in order to correct for the under or over representation of any particular grouping of buyers. Accounting for the above, the approach adopted was seen as the most appropriate means of obtaining the required information.

The decision to use an online tool for the quantitative component of the research was based, in the first place, on the knowledge that the commercial sex industry has largely moved online. At the same time, owing to widespread access to the internet in both Ireland and Finland, the risk from a coverage gap was minimal. This was further reduced through advertising the survey on a number of the most popular websites in Ireland and Finland. Moreover, the use of an online research tool was seen to offer advantages, particularly with regard the target population.

Web based research can assist in communicating with groups who are underrepresented in the general population, and difficult to contact owing to their 'involvement in undesirable or deviant interests or activities' (Monette et al, 2010, p. 192). This has previously been demonstrated in research on sex buyers. In the Canadian research project, John's Voice, it was reported that a web based research tools were the most effective method for collecting information on buyers, owing to the anonymity offered (Atchison, 2010, p. 7). A similar conclusion can be drawn from the research at hand. In both Ireland and Finland, in spite of a number of efforts, it was not possible to recruit buyers for face to face interviews. Using similar methods, however, it was possible to recruit over 250 buyers to answer online surveys.

Recognising the importance of anonymity to the target population, those who decided to participate in the research did not have to go through any security measure, which was seen as an important means of encouraging participation. Instead, the data was 'cleaned' following receipt of all responses. This involved checking the IP addresses of participants for duplicate responses. This approach ensured that the perceived anonymity offered by the online survey would not be undermined by a requirement to supply personal information such as an email address; a common security measure used in online surveys. Furthermore, as this security measure is most often used to protect against duplicate responses, a similar level of security 
was achieved using IP address checking.

In order to participate in the research, perspective participants were thus only required to click into advertisements placed on a number of popular websites in Ireland and Finland. Consequently, the researchers had no control over those who participated. Admittedly, this form of data collection can create difficulties, engendering a self-selection bias; wherein it is a specific characteristic or experience of a potential participant driving their involvement in research. The presence of a self-selection bias can lead to the under or over representation of particular segments of a target population and thus can make it difficult to draw reliable inferences. Yet, a characteristic commonly identified as influencing participation is a pre-existing interest in the research topic. With this in mind, it is safe to assume that those who purchase sex likely have a pre-existing interest in this topic. Moreover, taking into account the variation in the characteristics of those who responded to the online survey, and the similarities between these respondents and participants in previous, comparable research, there is little to suggest that the lack of control led to a selfselection bias.

The survey itself was comprised of 19 questions. In spite of the survey being aimed at buyers, it was also open to non-buyers. All participants were asked about their gender; relationship status; education level; place of residency; age; and income. The survey then asked participants whether they had ever purchased sex. For those who responded 'no', they were directed to a question on what had deterred them from doing so. The options available were 'it is too expensive'; 'it is illegal'; 'I am in a relationship'; 'diseases'; 'I would be too embarrassed'; 'it is against my beliefs'; 'there is nowhere I could buy sex'; and 'getting caught and publically named'. Participants who reported purchasing sex, and who thus belonged to the category of 'buyers', were guided to a number of questions on their experiences in purchasing sex. These included from whom they had bought sex; where; how they had located the seller the last time they had purchased sex; where the transaction took place on this occasion; and the number of times they had purchased sex. Next, buyers were asked whether they had ever changed their mind because a seller appeared 'scared'; 'unwilling'; 'frightened'; 'controlled'; 'unhappy'; 'intimidated'; 'hurt or injured'; or 'too young'. Buyers were also asked whether they had ever reported suspicions that someone was being exploited or controlled. Finally, buyers were asked what measures they felt could act as an effective deterrent to the purchase of sex. The options available were, 'contracting a disease or having a bad experience'; 'being named and shamed in the local media'; 'being named and shamed on the internet'; 'being arrested'; 'a large fine'; 'having a letter sent to an employer'; 'having a letter sent to family members'; and 'having to attend an educational level'. Participants were asked whether these measures would deter them 'a little', 'a lot' or 'not at all'.

The first survey was conducted in Ireland between November 2011 and January 2012. This was followed by the Finnish survey in May 2012. In order to attract participants, advertisements were placed on a number of popular websites. 
Additionally, advertisement campaigns were run using Facebook.com. In both Ireland and Finland, advertising was managed by a third party with previous experience in marketing online research. In Ireland, advertisements placed online made 2,486,235 impressions. This number represents the total number of potential views of an advertisement. These resulted in 969 clicks, representing a click through rate (CTR) rate of $0.04 \%$. The CTR rate is the proportion of those who potentially saw an advertisement who proceeded to click on it. The CTR rate was marginally higher for the advertising campaign ran on Facebook.com. These advertisements made 1,655,578 impressions, resulting in 818 clicks; representing a CTR rate of $0.05 \%$. In Ireland, there were 1,557 clicks on all the advertisements placed online. Of those who clicked on the advertisement, 410 completed the survey. This represents a completion ratio of just above 26\%. In Finland, an advertisement campaign was run using Google AdWords. At the same time, the survey was advertised through Facebook.com. The Facebook.com advertising campaign had a CTR rate of $0.5 \%$, representing 334 clicks. The Google AdWords campaign had a CTR of 0.6\%, representing 637 clicks. Of the 971 users who clicked on an advertisement, 544 completed the survey. This represents a click to completion ratio of 56\%. Comparing the two it can be seen that the CTR and click to completion rate for Finland were higher than that for Ireland. It is not within the remit of this research to explain for this differentiation, though this could be attributed to the use of AdWords in Finland. Looking at the figures above, this was the most successful method for getting potential participants to click into the survey.

\section{Face to face interviews}

The qualitative component of the research consisted of semi-structured interviews with buyers. Initially, these interviews were to be conducted in Ireland, Finland, Bulgaria and Lithuania. Owing to a number of difficulties in recruiting buyers in Ireland and Finland, discussed below, it was only possible to conduct interviews in Bulgaria and Lithuania.

These interviews were based on a survey consisting of 57 questions and thus offered more scope for collecting more extensive information from buyers. The questionnaire was divided into a number of sections. The first section was concerned with the characteristics of buyers. This was followed by questions concerned with the buyer's first experience of purchasing sex. Next, buyers were asked on their most recent experience purchasing sex. Other areas covered included buyers general experiences when purchasing sex; their opinions and beliefs with regard the act of purchasing sex and those from whom they purchase sex; experiences of exploitation when purchasing sex; their use of internet pornography and how this impacted on their purchase of sex; their knowledge of human trafficking and how this impacts on their purchase of sex; and measures they felt could act as an effective deterrent 
to the purchase of sex.

Different methods for recruiting buyers were used in the four countries intending to carry out face to face interviews.

\section{Ireland}

In Ireland, a number of methods were used to recruit buyers for face to face interviews. In the first place, the online survey was used as a means of recruiting buyers for in depth interviews. The final question on the online survey asked buyers who were interested in participating further in the research to supply an email address. This was followed by an email inviting buyers to participate in a face to face to interview. Information on the project and interview were provided in this mail, along with an offer of financial consideration for the participant's time. Additionally, buyers were assured of confidentiality. The offer of consideration was based on a similar approach adopted in previous research on buyers. However, only a small number of buyers supplied their email addresses. Of these, only one buyer indicated that they would be willing to participate in an interview. This resulted in the only interview carried out in Ireland. Following on from this, an advertisement was placed on a popular website containing forums for discussion, boards.ie. This advertisement contained similar information to that provided to buyers who had provided their email addresses, described above. Additionally, a Facebook page was set up for recruiting buyers. Neither, however, resulted in contact from buyers. Finally, contact was made with counsellors specialising in sexual addiction. This was based on evidence that those suffering from sexual addiction often engage in what could be considered risky sexual behaviour, including the purchase of sex. At the request of one centre, information leaflets were supplied which included information on the project, interviews and contact details. These, however, did not result in any interviews. As a result of the above, a decision was made that the Irish component of the research would be based on the evidence from the online survey alone.

It is possible that the reluctance of buyers to participate in the research in Ireland may have resulted from the Irish political context. At the same time as the research was being conducted there was an on-going political discussion on the future of prostitution legislation in Ireland, led by the participating organisation in Ireland, which could have created apprehension amongst buyers to participate in the research.

\section{Finland}

Prior to recruiting buyers, the Finnish participating organisation sought advice from researchers at the University of Helsinki. They were informed that it would be difficult for them, as a women's organisation, to recruit buyers to participate in face to face interviews. The Finnish researchers first posted online advertisements on a popular website used for advertising the sale of sex, sexwork.net. While this advertisement did create discussion on the website, it did not result in any interviews. Advertisements were then placed on a popular Finnish online forum, suomi24.fi. In 
order to engage with buyers, a thread was also started on this site. In spite of these, no buyers expressed interest in participating in a face to face interview. In a final attempt to recruit buyers, advertising specialists were recruited and advertisements were published on both Facebook and Google. These advertisements ran for one week. These advertisements, however, did not result in any interviews. Following on from this, a decision was made to base the Finnish component of the research on the online survey. The above suggests that the fears expressed by the researchers at Helsinki University were accurate.

\section{Lithuania}

The Lithuanian participating organisation took a distinct approach to recruiting buyers for interviews. The Director of the organisation recruited final year students at a university to conduct interviews. Out of a number of applications to conduct the interviews, five students were chosen. These students received training in conducting the interviews and were required to familiarise themselves with the research and questionnaire. Of a number of methods used to recruit buyers for interviews, the only success came from advertising at a nightclub where one of the students worked. Moreover, this allowed for the research to be advertised via word of mouth. In total, 37 interviews were conducted. As will be discussed below, the majority of those who participated in the research in Lithuania were young, which suggests a bias arising from the method of recruiting participants. During the interviews researchers reported that buyers had flirted with and propositioned them. Looking at similar works, this does not appear to be an uncommon occurrence in this type of research.

\section{Bulgaria}

In order to recruit a wide and diverse sample and conduct information rich interviews the Bulgarian participating organisation used their network of NGOs throughout the country and recruited professional interviewers including psychologists, social workers, as well as a journalist. Interviews were conducted in towns including Haskovo, Pernik, Sofia, Bourgas and Varna. Different methods for recruiting buyers were used in each city. In Haskovo buyers were recruited through word of mouth; in Pernik interviews were advertised through a project supporting people recovering from addictions; in Varna a psychotherapist who conducted the interviews used her personal practice to advertise the research; while in Bourgas the research was advertised through a luxury car hire service and an outreach program working amongst the Roma population. In total, 36 buyers were recruited and interviewed throughout Bulgaria.

Once the interviews were conducted, the transcripts were translated and entered into excel sheets by the researchers in Ireland, which allowed for the data to be analysed and compared. 


\section{Findings}

The findings from the online surveys and interviews are discussed below. The discussion contained below is based on input from a total of 337 buyers, from Ireland $(n=58)$, Finland $(n=208)$, Lithuania $(n=34)$ and Bulgaria $(n=37)$ who participated in the research. The research project on which this paper is based included an online survey in Cyprus. Owing to a lack of available information on the methodology employed to recruit buyers - who represent the hard-to-reach population studied here - for this component of the research, however, the results from Cyprus have been excluded. Given the overall scale of the original research project, however, not all findings are presented. Rather, the findings and discussion contained below provide an overview of the research participants while focusing specifically on those areas where the buyers' experiences intersect with issues relating to trafficking in human beings.

\section{Participant profile}

Much like trafficking in human beings for sexual exploitation (Walby et al, 2016), the purchase of sex is a highly gendered practice, which is principally characterised by men purchasing sex from women (with smaller numbers of males purchasing sex from males, females purchasing sex from males, and females purchasing sex from females) (Sanders et al, 2009, pp. 75-78).

Mirroring such findings, the overwhelming majority of buyers who participated in the research were males who had purchased sex from female sellers. 98\% of respondents to the online survey in Ireland were male, while $92 \%$ of buyers in Finland were male. All of the interviews which took place in Bulgaria and Lithuania involved male participants. At the same time, the overwhelming majority of respondents reported purchasing sex from females. In Finland, $80 \%$ of buyers reported purchasing sex from female sellers. $81 \%$ of Irish buyers reported purchasing sex from females. Those buyers who participated in in-depth interviews in Bulgaria and Lithuania were not directly asked the gender of sellers they ordinarily visited; however, in describing their experiences they principally described them as being with female sellers.

\section{Witnessing exploitation and vulnerability}

Research on buyers' perceptions and understanding of exploitation and encounters with exploitation when purchasing sex shows that it is not uncommon for buyers to encounter sellers they believe are being exploited. For example, just over one quarter of buyers in a Scottish study had encountered sellers under the control of a pimp 
(Farley et al. 2011a). At the same time, however, only a handful of buyers in research conducted across Eastern Europe reported encountering buyers they believed were in situations of exploitation or who had been trafficked. It is important to note, on the other hand, that most of these buyers admitted that they would be unable to identify a trafficking victim as such, while those who reported they could, used indicators which would not be present in every case, such as body-guarded women, and women against whom violence had been committed (Bianchi et al. 2007).

In the research reported here, buyers were asked whether they had ever encountered a seller they believed was being exploited. Those responding to the online survey were also presented with a list of indicators, in order to identify the basis on which they believed the seller was being exploited. In Finland, 55 buyers identified 91 reasons they suspected a seller was being exploited. The most frequently stated reason was that the seller appeared 'too young', identified by nineteen buyers, followed by 18 buyers who believed that the seller appeared 'unwilling'. Other common answers included that a person appeared controlled, scared, unhappy, frightened, hurt/injured, or intimidated. Similarly, around one-quarter of Irish buyers encountered sellers they believed were being exploited. The reasons given by buyers for believing this was that the seller appeared 'controlled' $(n=6)$ and/ or 'unhappy' ( $n=5)$.

Only a small number of Bulgarian buyers reported that they had encountered sellers they believed to be exploited. Of the four Bulgarian buyers reported encountering sellers they believed were being exploited, one buyer reported encountering a minor. Another buyer reported that they had encountered someone who was there against their will. A third buyer reported that they had encountered someone he believed was being exploited, but did not provide any further information. The circumstances in which the fourth buyer encountered exploitation were unclear.

As with the Bulgarian interviews, only a small number of Lithuanian buyers reported encountering sellers they believed were being exploited. Four buyers reported that they had encountered a seller they believed was being exploited, and an additional three buyers were unsure if they had. Amongst the four buyers who believed they had encountered sellers being exploited, only two were willing to discuss the circumstances. One reported that the seller was underage, while the second buyer believed that the seller had been trafficked. Unfortunately, no further information was provided on why the buyer believed this to be the case. Only one buyer reported that they had contacted the authorities, this was the buyer who believed the seller was underage.

With regards to the interviews in Bulgaria and Lithuania, some interesting points arose in how buyers responded to this question. In the first place, there was evidence that buyers were reluctant to discuss such encounters. Amongst the small number of buyers who reported that they had encountered exploitation during the interviews in Bulgaria and Lithuania, few details were provided. One buyer flatly refused to give any details, and when asked the question he simply replied: 'Yes - once, but I 
do not want to get into details'. At the same time, rather than provide an answer, a small numbers of buyers skipped this question. Another group of answers to this question provided evidence that it is difficult for buyers to know whether they have encountered exploitation: 'Maybe, I did not ask them', 'I don't know, I didn't ask', and 'I don't know, I don't talk about life with them'.

In the data, a noticeable gap emerged between the number of buyers who reported encountering sellers they believed were being exploited and buyers who considered contacting authorities to report such fears. While 69 buyers in Finland and Ireland reported that they had encountered sellers they believed were being exploited; only 57 buyers in those countries reported that they had ever considered contacting authorities over fears that a seller was trafficked/ controlled. A similar gap emerged amongst buyers in Ireland. The gap is greater for those buyers who actually contacted authorities. In Bulgaria and Lithuania, of the eight buyers who reported that they had encountered sellers they believed were being exploited; only two reported this to the authorities. These buyers did not discuss their reluctance to contact authorities in detail. However, one buyer did state that it was out of fear of the sellers' pimp.

Owing to limitations, it is not possible to determine the overall number of buyers who actually contacted the authorities. At the same time, there are a number of factors which make it likely that buyers will overlook possible signs or indicators of exploitation, including indicators of human trafficking.

\section{Human trafficking}

Previous research has found that buyers regularly disregard dangers associated with prostitution, including situations where sellers are either underage or may be a victim of human trafficking (USAID, 2011). Focusing on human trafficking, research has found that buyers would not knowingly purchase sexual services from a trafficking victim, although this research did not establish the buyers' knowledge of human trafficking (Bianchi et al. 2007). In respect of laws specifically targeting buyers who knowingly purchase sexual services from trafficking victims, it has been suggested that their declarative force alone can make them effective (Gallagher, 2010). It can be presumed that this will be dependent on buyers' knowledge of any such law and their own consideration of human trafficking.

Criminalising the end users of victims of trafficking for sexual exploitation, the buyers, remains a controversial issue. Under the applicable European Union law, Article 18 (4) of Directive 2011/36/EU, knowledge of exploitation, on the part of the buyers, is required. This is how the provision has in general been transposed into the laws of EU Member. As a result, in order to prosecute buyers who have purchased sex from a trafficking victim; it must be shown that they were aware of the status of the seller. This relies on non-material evidence that is difficult to prove. It is believed, however, that knowledge of this provision will cause buyers to show 
greater concern for the status of the seller, and the possibility that they may be a victim of trafficking.

Our findings suggest that, irrespective of a buyers' knowledge of human trafficking as a crime and as a phenomenon, it is unlikely that they will consider the possibility that a seller may be a victim of trafficking when purchasing sex. Similarly, knowledge of existing laws specifically targeting buyers of sexual services from trafficking victims appear to have no impact on buyers' consideration of human trafficking in the act of purchasing of sex. Our research in this area draws on the findings of the interviews in Bulgaria and Lithuania.

Bulgarian buyers' knowledge of human trafficking varied. Fifteen buyers reported 'some' or a 'good' level of knowledge, nine reported they had 'poor' or 'minimal' knowledge, and five reported no knowledge either directly or indirectly in their response. Five buyers provided no answer. Amongst those with reported knowledge of trafficking, there was a wide spectrum with regard to how they understood the practice. At the lower end of the spectrum, buyers had no real understanding of the trafficking, while, at higher end, they were aware of EU law on the issue; recognised that trafficking could involve deception over conditions of work, rather than types of work; and recognised that women trafficked into the sex industry can be aware of the type of work they are to perform, but not the conditions they will have to work in. As one buyer stated:

'If a woman is a victim of sex trafficking, maybe she knew she'd be working in the sex industry. But she would not have known that she'd be deprived of her freedom, as well as from the money she earns.'

In Lithuania, the majority of buyers reported knowledge of human trafficking. Fifteen buyers reported either 'good' or 'some' knowledge of human trafficking and a further nine buyers reported either minimal or 'poor' knowledge. Eight reported no knowledge either directly or indirectly through their responses. A number of trends emerged in the buyers understanding of human trafficking. For many, human trafficking was an international, rather than a domestic problem. Interestingly, almost a quarter of buyers who had some knowledge of human trafficking reported that it did not occur in Lithuania. Treating human trafficking as an international problem alone could indicate an understanding of the issue, which revolves around 'transport', or the crossing of borders. If this were so, buyers could overlook instances of domestic trafficking. Of those buyers who had either 'good' or 'some' knowledge of the practice, a number showed they understood many of the processes used by traffickers. According to one such buyer: 'it is common-trapped with offers of job to be a stripper and then become a prostitute'. Another buyer stated that: 'It happens all over the world - In Lithuania, girls from the most disadvantaged families are seduced by promises of jobs etc...' Similarly, according to another buyer: 'Yes - [had] some knowledge - talked about false job offers, confiscation of official documents and forced work'. There were also 
some buyers who were uncomfortable discussing human trafficking. One buyer stated: 'I'm not interested in anything about it'.

The vast majority of buyers were aware that it is a criminal offence, under Bulgarian law, to purchase sex from a trafficked person. Twenty-eight buyers were aware of the offence. Yet, in spite of all the above, the overwhelming majority of Bulgarian buyers had never considered human trafficking when purchasing sex. Only one buyer who reported not considering human trafficking when purchasing sex elaborated on his answer, expressing a belief that doing so could operate as a deterrent:

Maybe If I have thought about this, I would not have used such services.

In Lithuania, 27 buyers reported that they were aware that it was an offence to purchase sex from a trafficking victim. Yet, despite their knowledge of this offence and the crime of human trafficking, only three buyers had ever considered human trafficking when purchasing sex:

No - you are just buying a service

I will think about whether she is clean. I will not think about whether she has been trafficked.

This is not my concern.

As such, it appears that buyers rarely consider human trafficking when purchasing sex, irrespective of their knowledge of the issue or laws criminalising the purchase of sex from trafficking victims. These findings can likely be attributed to buyers' views of prostitution and sellers.

\section{Views on prostitution and sellers}

Research on how buyers view the act of purchasing sex shows that this is often viewed in consumerist terms (USAID 2011; Kelly et al. 2009; Marttila, 2003;). Research also shows that this is an expression of power where women are under the control of men (Marttila, 2003) and power arises from a sense of dominance (Farley et al. 2011b). Related to this is research showing that buyers view the purchasing of sex as a construct of masculinity (Kelly et al. 2009), described as a 'coming of manhood thing' linked to a male imperative or privilege (Durchslag and Goswami, 2008).

Regarding the views of buyers of the women who sell sex, research has found that buyers are both judgemental and often fail to comprehend how sellers came to be involved in prostitution, despite the fact that they would not wish for a family member or close friend to become involved in the sale of sex (Durchslag and Goswami, 2008). Buyers do, however, recognise some of the reasons why sellers are involved in prostitution, such as childhood abuse and desperation (Durchslag and Goswami, 2008), although their apprehension of such realities has been found not to be consistent with their actual occurrence (Farley et al. 2009). Thus, in one study, while a majority of buyers reported that relatively few sellers had suffered 
childhood abuse, the actual proportion could be as high as 90\% (Farley et al. 2009).

A more worrying lack of empathy for sellers emerges in the Bianchi et al (2008) study which found a lack of sympathy for sellers trafficked into the sex industry, based on the belief that they had freely chosen to become involved in the industry in the first place.

Based on the data from the interviews conducted in Bulgaria and Lithuania, discussed below, our findings confirm that buyers have a complex view of the act of purchasing sex and those involved in the sale of sex. On the one hand, they overwhelmingly believe that the sale of sex is a transaction between two consenting adults. Yet, it is not something they would want any close friend or family member to become involved in. Most buyers reported viewing sellers as being different from other women. At the same time, their reported views of sellers were predominantly as a sex object which helps to differentiate sellers from other women in the eyes of buyers.

In respect of whether buyers in Bulgaria believed prostitution was an act between consenting adults, only four buyers disagreed and one buyer strongly disagreed with this statement. The overwhelming majority, sixteen buyers, agreed and eleven strongly agreed with this statement. While these findings are perhaps unsurprising, they do indicate that buyers approach the act of purchasing sex with a presumption of consent. A similar majority of Lithuanian buyers viewed prostitution as an act between two consenting adults, although a small number of buyers disagreed with the statement. No buyers strongly disagreed with it. Just over three-quarters of buyers either agreed or strongly agreed with the statement.

In respect of how buyers viewed sellers, the most often cited view of sellers was as a sexual object $(n=19)$. In Lithuania, the majority of buyers viewed sellers as business women $(n=9)$. This, however, was followed closely by buyers who viewed sellers as sexual objects $(n=6)$ and who didn't think of them as a person $(n=6)$ thus suggesting a less empowering view of sellers.

The interviews further revealed that the overwhelming majority of buyers believed that sellers were different from other women. When asked how they felt about the statement, 'women in prostitution are different from other women', 22 buyers in Bulgaria either agreed or strongly agreed, while only seven buyers either disagreed or strongly disagreed. In Lithuania, the majority of buyers, representing just under three-fifths of respondents, either agreed or strongly agreed with this statement.

This differentiation between sellers and other women also emerged in respect of how buyers reported they would feel if a relative or close friend started selling sex. In Bulgaria, 23 buyers stated that this would make them feel bad. This feeling was expressed in a number of ways. Words including 'horrible', 'disgusting' and 'angry' were regularly used to describe this. A small number - five buyers - stated that they would not mind, providing it was voluntary. These feelings suggest a more complex view on the act of prostitution than it being an act between consenting adults. The same number of buyers in Lithuania $(n=23)$ indicated that it would not be good. A 
number of themes emerged in the answers provided by buyers to this question. In the first place, a number of buyers reported that they would feel 'shame', whereas other buyers stated that they would try and 'help' - meaning they would try and help them stop.

Combined, the sense of privilege linked to the purchase of sex, the lack of empathy for sellers, who are often viewed in consumerist terms or as objects and as different from other women, and the presumption of consent, which is present in how many buyers view the purchase of sex overall, likely makes it difficult for buyers to recognise indicators of exploitation, or consider the circumstances of the seller when purchasing sex.

\section{Conclusion}

The study of sex buyers represents a number of challenges for researchers. First and foremost, owing to the documented importance of anonymity to buyers, it is difficult to engage with this hard-to-reach population. Our research findings suggest that such difficulties can be overcome using research tools which allow buyers to maintain anonymity. In particular, the use of online surveys appears to offer a number of advantages, increasing the likelihood that buyers will participate in such research. Furthermore, taking into account the apparent reluctance of many buyers to discuss subjects including exploitation during face to face interviews, online research may offer an important tool for studying buyer's experience of exploitation in the commercial sex industry. In order to ensure the detail necessary to understand these issues, however, it will still be necessary to conduct in depth interviews. To increase participation in such interviews and a diverse sample of buyers, it will be incumbent on researchers to consider, where relevant, the likely perception of their own organisation amongst buyers, and the impact of the wider political climate as it relates to the issue of prostitution. At the same time, it will be beneficial to use a number of methods to recruit buyers, in order to ensure a diverse sample, similar to those who participated in the online surveys and in the research in Bulgaria.

The findings from this research highlight the importance of challenging the general demand for the purchase of sex in order to challenge the demand that fosters exploitation and leads to trafficking for sexual exploitation. Based on our findings it is apparent that a large number of buyers encounter sellers they believe are being exploited, thus challenging the idea that exploitation, and trafficking, only occurs in certain areas of the commercial sex industry. Furthermore, owing to the views of buyers, the pre-existing presumption of consent, and a lack of consideration of human trafficking when purchasing sex, it is probable that buyers encounter exploited sellers, without recognising them as such. This not only challenges the view that buyers can act as an important defence against exploitation in the industry, but 
further underlines the importance of targeting general demand in the sex industry in order to reduce exploitation and trafficking. Consequently, there is a need to focus on measures which can discourage the purchase of sex.

\section{References}

Anderson, B. and Davidson, J. O. C. (2002) Trafficking-a Demand Led Problem? Sweden: Save the Children.

Atchison, C, (2010) Report of the Preliminary Findings for Johns' Voice: A Study of Adult Canadian Sex Buyers, January 2010 [Accessed on 31 May 2018 at http://www.johnsvoice.ca/docs/ JOHNS_VOICE_GENERAL_RESULTS_EXECUTIVE_SUMMARY_FINAL_DIST.pdf]

Bianchi, G., Popper, M. And Luksik, I. (2007) Between demand and dupply: a regional analysis of the supply and demand for sex services and trafficking in Hungary, Poland, Slovakia and Slovenia. Bratislava: Department of Social and Biological Communication and Centre of Excellence (COPART)/ Slovak Academy of Science.

Cho, S. Y., Dreher, A. and Neumayer, E. (2013) Does legalized prostitution increase human trafficking? World Development, 41, 67-82.

Council of Europe (2005) Convention on Action against Trafficking in Human Beings. Council of Europe Treaty Series - No. 197, 16 May 2005 [Accessed on 28 May 2018 at https:// rm.coe.int/168008371d]

Danailova-Trainor, G. and Belser, P. (2006) Globalization and the illicit market for human trafficking: an empirical analysis of supply and demand. ILO

Durchslag, R. and Goswami, S. (2008) Deconstructing the Demand for Prostitution: Preliminary Insights from Interviews with Men Who Purchase Sex, Chicago Alliance against Sexual Exploitation, May 2008. [Accessed on 20 March 2018 at http://g.virbcdn.com/_f/files/2e/ FileItem-149843-JohnsWhoPurchaseInsideVersusOutside.pdf]

European Union (2011) Directive 2011/36/EU on preventing and combating trafficking in human beings and protecting its victims. European Commission [Accessed on 28 May 2018 at https://ec.europa.eu/anti-trafficking/legislation-and-case-law-eu-legislationcriminal-law/directive-201136eu_en]

Farley, M., Bindel, J. and Golding, J.M. (2009) Men Who Buy Sex: Who They Buy and What They Know? Eaves London, Prostitution Research \& Education, December 2009, Available from: http://il.cmsfiles.com/eaves/2012/04/MenWhoBuySex-89396b.pdf [Accessed 20 March 2018]

Farley, M., Anderson, L., Golding, J.M. and Macleod J.(2011a) Attitudes and Social Characteristics of Men Who buy Sex in Scotland, Psychological Trauma: Theory, Research, Practice, and Policy, March 28, 2011, Available from: [Accessed on 20 March 2018 at http://www.prostitutionresearch.com/pdfs/Farley,Macleod\%20et\%20al\%202011\%20 Men\%20Who\%20Buy\%20Sex\%20In\%20Scotland.pdf]

Farley, M., Schuckman, E., Golding, J.M., Houser, K., Jarrett, L., Qualliotine, P. and Decker, 
M.(2011b) Comparing Sex Buyers with Men Who Do not Buy Sex: 'You Can Have a Good Time with the Servitude' vs. 'You're Supporting a System of Degradation', Psychologists for Social Responsibility Annual Conference, Boston, July 15, 2011 [Accessed on 20 March 2018at http://www.prostitutionresearch.com/pdfs/Farleyetal2011ComparingSexBuyers.pdf]] Gallagher, A.T. (2010) International Law of Human Trafficking. Cambridge University Press Hughes, D. M. (2004) Best practices to address the demand side of sex trafficking. University of Rhode Island

Hughes, D. M. (2005) The demand for victims of sex trafficking. University of Rhode Island

Kelleher, P., O'Connor, M., Kelleher, C. and Pillinger, J. (2009) Globalisation, Sex Trafficking and Prostitution: The Experiences of Migrant Women in Ireland, Immigrant Council of Ireland [ Accessed on 31 May 2018 at http://emn.ie/files/p_201211231126542009_Trafficking_ Report_ICI.pdf] []

Kelly, L., Coy, M. and Davenport, R. (2009) Shifting Sands: A Comparison of Prostitution Regimes Across Nine Countries. London Metropolitan University, Child \& Woman Abuse Studies Unit (CWASU) [Accessed on 20 March 2018 at http://cwasu.org/wp-content/ uploads/2016/07/shifting-sands-published-version.pdf]

Marttila, A. (2003) Consuming Sex-Finnish Male Clients and Russian Baltic Prostitutes. Presented at Gender and Power in New Europe, the 5th European Feminist Research Conference, August 20-24, 2003 Lund University, Sweden [Accessed on 20 March 2018 at http:// prostitution.procon.org/sourcefiles/consuming-sex-finnish-male-clients-and-russianand-baltic-prostitution.pdf]

Monette, D.R., Sullivan, T.J. and DeJong, C.R. (2010) Applied social research: Tool for the human services. Belmont, CA: Brooks/Cole.

Sanders, T., O'Neill, M. and Pitcher, J. (2009) Prostitution: Sex Work, Policy and Politics. Sage: London

USAID (2011) Tackling the Demand that Fosters Human Trafficking. Produced for the Social Transition Team.

Walby, S., Apitzsch, B., Armstrong, J., Balderston, S., Follis, K., Francis, B., Kelly, L., MayChahal, C., Rashid, A., Shire, K., Towers, J., and Tunte, M. (2016) Study on the gender dimension of trafficking in human beings (European Commission) [Accessed on 31 May 2018 at http://ec.europa.eu/anti-trafficking/sites/antitrafficking/files/study_on_the_gender_ dimension_of_trafficking_in_human_beings._final_report.pdf]

Wheaton, E. M., Schauer, E. J. and Galli, T. V. (2010) Economics of human trafficking. International Migration, 48, 4, 114-141

Yonkova, N. and Keegan E. (2014) STOP Traffick: Tackling Demand for Sexual Services of Trafficked Women and Girls (Immigrant Council of Ireland: Dublin) [Accessed on 20 March 2018 at http://www.stoptraffick.ie/wp-content/uploads/2013/03/STOPTRAFFICK-full-report.pdf] 